Check for updates

Montreal, Canada

Cite this as: BMJ 2021;373:n1111 http://dx.doi.org/10.1136/bmi.n1111 Published: 28 April 2021

\title{
Covid-19: US will send 60 million AstraZeneca doses abroad as domestic demand falls
}

\section{Owen Dyer}

The Biden administration has announced that the US will send as many as 60 million doses of the AstraZeneca coronavirus vaccine to countries in need-effectively conceding that the vaccine, developed at Oxford University, UK, will never be offered to the US public.

"We do not need to use AstraZeneca in our fight against covid," the White House press secretary, Jen Psaki, told reporters.

The administration has been under international pressure to do more for poor countries, but it is bound by an election promise to not make any US vaccination wait because of aid given abroad. The AstraZeneca vaccine became an obvious candidate for foreign donations as it became clear that offering it to the US population would lead to higher rates of vaccine refusal.

US vaccinations have proceeded swiftly in recent weeks, and $53 \%$ of adults have now received at least one dose. But as more and more willing recipients move into the "vaccinated" column, the proportion of unwilling people among the unvaccinated also keeps climbing.

A Washington Post-ABC News poll found that, among people who were still unvaccinated, $55 \%$ said that they would probably or definitely not get vaccinated. ${ }^{1}$ But when asked whether they would take the Johnson \& Johnson (J\&J) vaccine-which, like AstraZeneca's, was paused while reports of blood clots were investigated-the proportion who were unwilling rose to $73 \%$.

Asked whether they considered the Pfizer vaccine safe, $73 \%$ of Americans polled said that it was, but only $46 \%$ said the same of the J\&J vaccine. The poll did not include the AstraZeneca vaccine, but with its parallel history it would be expected to face a similar deficit of trust.

\section{Recipient countries}

The poll seems to undermine the arguments of people who said that pausing vaccines would build public confidence, as $24 \%$ said that they had lost confidence as a result of the J\&J pause, while only $1 \%$ said that they had gained it. Given the difficulties of vaccinating the remaining population and the large stockpiles of Pfizer and Moderna vaccines available to the US government, the J\&J vaccine could also feature heavily in US donations abroad.

Where the 60 million AstraZeneca doses will go is not clear. President Biden spoke to the Indian prime minister, Narendra Modi, this week, but Modi did not request whole doses, instead reiterating a previous request for the US to release more raw materials to India's vaccine makers. Any shipments abroad will have to wait on the vaccine's approval by the US Food and Drug Administration.

Concern is widespread that uptake in the recipient countries could be harmed by the perception that the US is giving away a vaccine that its own people refused to take.

South Africa has already stopped using the AstraZeneca vaccine and sold its existing stock, after trials suggested that it was almost completely ineffective against the country's prevalent B.1.351 strain, also known as the $501 Y . V 2$ variant. That variant has been found in at least 32 countries, though mostly in small numbers.

\section{US pays people to accept vaccination}

Meanwhile, in the US, increasingly imaginative methods are being adopted to persuade people holding out on being vaccinated to come in for their shot. Universities are offering gift cards and grants, while several corporations and restaurants are offering free drinks or meals to customers who present proof of vaccination.

Polling shows that vaccine refusers skew young and Republican. West Virginia, a heavily Republican state that is still seeing hospital admissions rise amid widespread refusals, announced on 27 April that it would start giving $\$ 100$ ( $€ 72 ; € 83)$ savings bonds to any resident aged under 35 who gets vaccinated.

Peter Hotez, a vaccine expert at Baylor College of Medicine in Houston, Texas, told the Washington Post that he supported the idea. "We're struggling, and we need innovative ways of reaching the high bar for population immunity," he said.

But he added, "The fact that we as a country have to beg or pay or bribe people right now to take this lifesaving vaccine, the optics are awful internationally. We look like a nation of adolescents, especially at a time when India, Africa, and most of the world are clamouring for more vaccine supply."

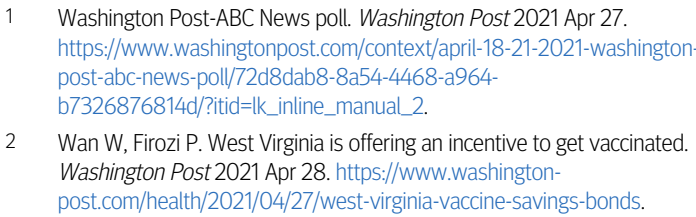

This article is made freely available for use in accordance with BMJ's website terms and conditions for the duration of the covid-19 pandemic or until otherwise determined by BMJ. You may use, download and print the article for any lawful, non-commercial purpose (including text and data mining) provided that all copyright notices and trade marks are retained. 